\title{
ESTUDO DE INTERAÇÃO SELETIVA DE HEMATITA EM RELAÇÃO AO QUARTZO*
}

Elaynne Rohem Peçanha ${ }^{1}$ Marisa Bezerra de Mello Monte ${ }^{2}$ Maurício Leonardo Torem ${ }^{3}$

\section{Resumo}

Com o objetivo de estudar a interação da hematita com biorreagente de flotação (Bacillus subtilis), foram realizados experimentos de ângulo de contato. Após a interação com o biorreagente, a superfície da hematita apresentou uma hidrofobicidade apresentando um valor de $46,0^{\circ}$. Os experimentos de potencial zeta mostraram uma interação acentuada entre o reagente e o mineral na faixa de $\mathrm{pH}$ alcalina com deslocamento do ponto isoelétrico da hematita. Ensaios de microflotação foram conduzidos em tubo de Hallimond modificado, em pH 6, com uma recuperação de, aproximadamente, $80 \%$. As teorias DLVO e X-DLVO foram aplicadas para avaliar as energias de interação entre o reagente e os minerais. As duas teorias foram capazes de prever a interação que ocorre entre o biorreagente e a hematita. Os resultados evidenciaram o uso promissor do reagente na flotação direta de hematita.

Palavras-chave: Hematita; Quartzo, Teoria X-DLVO; Bioflotação.

\section{INTERACTION STUDY SELECTIVE HEMATITE IN RELATION TO QUARTZ Abstract}

In order to study the interaction of hematite with a bioreagent flotation (Bacillus subtilis), contact angle measurements angle were performed. After interaction with the bioreagent, the hematite surface has presented hydrophobicicity showed a contact angle value of the 46,0 . The zeta potential experiments showed marked interaction between the bioreagent and the mineral in the alkaline $\mathrm{pH}$ range with displacement of the isoelectric point of charge of the hematite. Microflotation tests were conducted in modified Hallimond tube, at $\mathrm{pH} 6$, with $80 \%$ of hematite recovery. The DLVO and X-DLVO theories were applied to evaluate the energy of interaction between the reagent and minerals. Two theories have also been able to predict the interaction between the reagent and hematite. The results show the promising use of the reagent in direct flotation of hematite.

Keywords: Hematite; Quartz; X-DLVO theory; Bioflotation.

1 Gestora Ambiental, M. Sc., Pesquisadora Bolsista, Coordenação de Processamento Mineral, Centro de Tecnologia Mineral, Rio de Janeiro, RJ, Brasil.

2 Engenheira Química, D. Sc., Pesquisador Titular, Instituto Tecnológico VALE, Ouro Preto, MG, Brasil.

3 Engenheiro Metalúrgico, D. Sc., Professor Associado, Departamento de Engenharia Química e de Materiais, Pontifícia Universidade Católica do Rio de Janeiro, Rio de Janeiro, RJ, Brasil. 


\section{INTRODUÇÃO}

A demanda mundial crescente por matérias primas levou a exploração e processamento de minérios de baixo teor, especialmente para metais base, como é 0 caso do ferro. A combinação de especificações mais rigorosas para a produção de concentrados aliadas a uma legislação mais rígida incentivou a inúmeras investigações para encontrar outras técnicas de processamento e reagentes de flotação mais adequados (GERICKE e GOVENDER, 2011; MESQUITA et al., 2003). Os minérios de ferro brasileiros, conhecidos por itabiritos, são compostos essencialmente por hematita e quartzo (CARVALHO et al., 2014), e, utiliza-se o processo de flotação nas plantas de processamento quando se faz necessário o enriquecimento do mineral minério (MESQUITA, 2003).

Entre os problemas enfrentados pelas plantas de flotação, merecem destaque as elevadas perdas de partículas finas de hematita, nos rejeitos, assim como contaminação do concentrado por partículas grossas $(+74 \mu \mathrm{m})$ de quartzo. Por razões econômicas e ambientais, a necessidade de recuperação da massa de hematita contida no rejeito incentiva a pesquisa de experimentos relacionados à flotação de óxido de ferro (hematita) (BROD, 2012).

O estudo das propriedades de superfície, como hidrofobicidade e potencial zeta das partículas minerais bem como a previsão termodinâmica das energias de interação entre mineral e reagente tornam-se importantes, uma vez que a partir desses princípios, podem-se obter informações sobre a seletividade necessária ao processo de concentração mineral (VILINSKA, 2007).

No presente trabalho a aplicação de um reagente específico (Bacillus subtilis) foi investigada para propor um novo sistema de flotação seletiva da hematita em relação ao quartzo. A adesão entre o reagente e as superfícies da hematita e do quartzo foi estudada em detalhe. Fez-se uso do cálculo da energia de interação, utilizando as teorias DLVO e DLVO estendida.

\section{MATERIAIS E MÉTODOS}

\subsection{Amostras Minerais}

Amostras minerais altamente puras de hematita e quartzo foram adquiridas por um fornecedor local da cidade de Belo Horizonte (MG). A pureza da hematita e do quartzo foram apuradas para com 96,8\% e 99,3\%, respectivamente, através de análise de Fluorescência de Raios X.. As amostras foram cominuídas em britador de mandíbulas e seguiram para peneiramento a úmido para obtenção das frações desejadas (Tabela 1). Estas frações foram suspensas em solução de $\mathrm{KOH}\left(1.10^{-2} \mathrm{M}\right)$ com agitação magnética por 3 horas. Posteriormente, foram lavadas repetidamente com água Milli-Q até chegar ao pH desta mesma água. Estas duas etapas objetivam limpar a superfície das partículas.

Tabela 1. Tamanho de partícula para cada ensaio realizado

\begin{tabular}{cc}
\hline TAMANHO DA PARTÍCULA & EXPERIMENTO \\
\hline $74 \mu \mathrm{m}-106 \mu \mathrm{m}$ & Flotação individual, FR-X. \\
$<20 \mu \mathrm{m}$ & Potencial zeta \\
\hline
\end{tabular}




\subsection{Ensaios de Mobilidade Eletroforética}

As medidas de potencial zeta dos minerais e do reagente de estudo foram determinadas no equipamento Malvern-Zetasizer (Malvern Instruments, UK). A concentração do mineral e do reagente foram ambas de $100 \mathrm{mg} \cdot \mathrm{L}^{-1}$, e usou-se como eletrólito indiferente $\mathrm{NaCl} 10^{-3} \mathrm{M}$. O pH foi ajustado a partir de soluções diluídas de $\mathrm{HCl}$ e $\mathrm{NaOH}$. A avaliação dos perfis de potencial zeta para os minerais foi realizada antes e após a interação com o reagente.

\subsection{Ensaios de Ângulo de Contato}

Ensaios para determinação de ângulo de contato, que indicam hidrofobicidade ou hidrofilicidade de uma amostra, foram realizados a partir do Goniômetro modelo Ramé-Hart da COPPE pelo método da gota séssil. O estudo experimental consistiu das medidas de ângulo de contato envolvendo gotas de $2 \mu \mathrm{L}$ de água Milli-Q, a pH 6 , nas interfaces mineral/ar e reagente/ar. Três peças de hematita e quartzo, de cerca de $1 \times 1 \times 2 \mathrm{~cm}$, foram selecionadas para fixação em resina epóxi. Depois de fixadas, as superfícies foram deixadas em solução de $\mathrm{KOH} 1 \mathrm{M}$ por 24 horas e lavadas sucessivamente com água Milli-Q. Já, para os ensaios referentes a cada mineral adaptado ao reagente, seguiu-se a metodologia de adicionar $3 \mathrm{~mL}$ do mesmo, de concentração conhecida, na superfície mineral fixada à resina epóxi e deixou-se em repouso por 30 minutos. Posteriormente, a superfície foi lavada repetidas vezes com água Milli-Q e seca em estufa a $30{ }^{\circ} \mathrm{C}$. Quando a temperatura da superfície entrou em equilíbrio com a temperatura ambiente, as amostras seguiram para ensaios de ângulo de contato.

O ângulo de contato do reagente também foi determinado. Por se tratar de um colóide, o preparo da superfície seguiu a metodologia utilizada por Sharma e Rao (2003), onde $1 \mathrm{~mL}$ do reagente (de concentração conhecida) foi filtrado a vácuo em millipore de 0,45 $\mu \mathrm{m}$. Posteriormente, este millipore foi retirado com cuidado do filtro, colocado em placa Petri e seco a vácuo em dessecador à temperatura ambiente. Cada millipore que continha o reagente foi cortado e aderido com fita dupla face em lâmina de vidro.

Para estudar a interação entre dois sólidos pela teoria DLVO e X-DLVO faz-se necessário calcular as tensões superficiais de cada partícula $\left(\gamma_{\mathrm{s}}\right)$, composto pelo somatório entre a tensão ácido-base $\left(\gamma_{s}{ }^{\mathrm{AB}}\right)$ e a tensão Lifshitz-van der Waals do sólido $\left(\gamma_{\mathrm{s}}^{\mathrm{LW}}\right)$. Na tabela 2 apresentam-se os líquidos utilizados bem como suas constantes.

Tabela 2. Valores das componentes de energia de doação de elétrons, acepção de elétrons, ácidobase, Lifshitz-van der Walls e energia total para os respectivos líquidos utilizados nos ensaios de ângulo de contato.

\begin{tabular}{cccccc}
\hline CONSTANTE $\left(\mathbf{m J . m}^{-2}\right)$ & $\gamma^{-}$ & $\boldsymbol{\gamma}^{+}$ & $\boldsymbol{\gamma}^{\boldsymbol{A B}}$ & $\boldsymbol{\gamma}^{\boldsymbol{L W}}$ & $\gamma_{\boldsymbol{L}}=\boldsymbol{\gamma}^{\text {Total }}$ \\
\hline Glicerol & 57,4 & 3,92 & 30 & 34 & 64 \\
\hline Água & 25,5 & 25,5 & 51 & 21,8 & 72,8 \\
\hline Diiodometano & $<0,1$ & $<0,1$ & $\approx 0$ & 50,8 & 50,8 \\
\hline
\end{tabular}




\subsection{Ensaios de Microflotação}

Os testes de microflotação foram realizados em tubo de Hallimond modificado. A vazão de ar foi controlada por um rotâmetro previamente calibrado por bolhômetro, garantindo uma vazão de $15 \mathrm{~mL}$. $\mathrm{min}^{-1}$. Visando manter as partículas em suspensão, foi utilizada agitação magnética com $792 \mathrm{rpm}$. O condicionamento foi realizado na própria célula com $0,7 \mathrm{~g}$ da amostra mineral, $90 \mathrm{~mL}$ de eletrólito $\left(\mathrm{NaCl} 10^{-3} \mathrm{~mol}^{-\mathrm{L}^{-1}}\right) \mathrm{e}$ uma concentração determinada do reagente. Tanto o tempo de flotação como o de condicionamento foi de 5 minutos e o volume total da célula foi de $175 \mathrm{~mL}$. Os ensaios foram realizados em duplicata em $\mathrm{pH} 6$ e o ajuste de $\mathrm{pH}$ foi realizado a partir de soluções diluídas de $\mathrm{HCl}$ e $\mathrm{NaOH}$.

\subsection{Estimativa das Energias de Interação}

A teoria DLVO clássica considera a interação como um somatório de forças eletrostáticas e de van der Waals (BOTERO, 2008). Considerando a superfície do reagente uma esfera e a dos minerais uma superfície plana, a contribuição eletrostática (GELE) entre mineral e reagente é dado pela equação 1 e a de van der Waals $\left(G_{a d w}\right)$ pela equação 2.

$$
\begin{gathered}
G_{E L E}=\pi \varepsilon \varepsilon_{0} r\left[2 \zeta_{1} \zeta_{2} \ln \left(\frac{1+e^{-k H}}{1-e^{-k H}}\right)+\left(\zeta_{1}^{2}+\zeta_{2}^{2}\right) \ln \left(1-e^{-2 k H}\right)\right] \\
G_{v d W}=-\frac{A_{132} r}{6 H}
\end{gathered}
$$

Onde, $\varepsilon_{0}$ é a permissividade sob vácuo 8,85.10-12 $\left(\mathrm{C}^{2}-\mathrm{J}^{-1} \mathrm{~m}^{-1}\right)$, $\varepsilon$ é a constante dieléctrica do meio 79 ; $r$ é o raio equivalente do reagente $\left(1,95.10^{-6}(\mathrm{~m})\right)$; $\zeta_{1}$ e $\zeta_{2}$ são os valores do potencial zeta para o reagente e partículas minerais, respectivamente, (V); 1/k é o comprimento de Debye-Hückel (nm); H é a distância entre a superfície das partículas e de células microbianas (nm); A132 é a constante de Hamaker para o sistema reagente-água-mineral, que por sua vez é determinado pela equação 3.

$$
A_{132}=\left(\sqrt{A_{11}}-\sqrt{A_{33}}\right)\left(\sqrt{A_{22}}-\sqrt{A_{33}}\right)
$$

A constante de Hamaker do reagente $\left(A_{11}\right)$ e das partículas minerais $\left(A_{22}\right)$ foram calculadas a partir dos ângulos de contacto com o solvente apolar e pela equação 4.

$$
A_{11}=24 \pi \gamma_{S}^{L W}\left(d_{o}\right)^{2}
$$

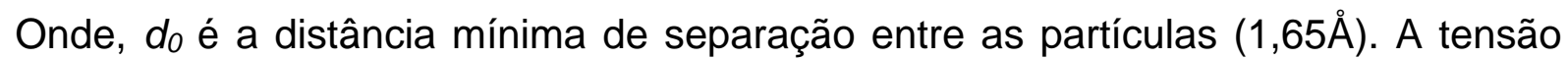
Lifshitz-van der Waals do sólido ( $\gamma_{s}^{L W}$ ) é calculada pela equação 5 .

$$
\gamma_{L G}(1+\cos \theta)=2 \sqrt{\left(\gamma_{S}^{L W} \gamma_{L}^{L W}\right)}
$$

A aproximação termodinâmica considera a variação de energia livre de adesão total para um sistema (equação 6) ( $\Delta G^{\text {Total }}$ ads ) como o somatório da variação de energia livre de adesão pela contribuição apolar (equação 7) $\left(\Delta G^{\mathrm{LW}}\right.$ ads) e polar (equação 8) $\left(\Delta G^{\mathrm{AB}}\right.$ ads). 


$$
\begin{gathered}
\Delta G_{\text {adh }}^{\text {Total }}=\Delta G_{\text {adh }}^{L W}+\Delta G_{\text {adh }}^{A B} \\
\Delta G_{a d h}^{L W}=-2\left(\sqrt{\gamma_{r}^{L W}}-\sqrt{\gamma_{l}^{L W}}\right)\left(\sqrt{\gamma_{m}^{L W}}-\sqrt{\gamma_{l}^{L W}}\right) \\
\Delta G_{a d h}^{A B}=-2\left(\sqrt{\gamma_{r}^{A B}}-\sqrt{\gamma_{l}^{A B}}\right)\left(\sqrt{\gamma_{m}^{A B}}-\sqrt{\gamma_{l}^{A B}}\right)
\end{gathered}
$$

Onde $\gamma$ representa a tensão de superfície; $r$ o reagente; $m$ a partícula mineral; LW a consideração Lifshitz-van der Waals e $A B$ a consideração ácido-base. A tensão de superfície $A B$ para um sólido foi calculada pelas equações 9 e 10.

$$
\begin{gathered}
\gamma_{L G}(1+\cos \theta)=2\left(\sqrt{\left(\gamma_{S}^{L W} \gamma_{L}^{L W}\right)}+\sqrt{\left(\gamma_{S}^{+} \gamma_{L}^{-}\right)}+\sqrt{\left(\gamma_{s}^{-} \gamma_{L}^{+}\right)}\right) \\
\gamma_{S}^{A B}=2 \sqrt{\gamma_{S}^{+} \gamma_{L}^{-}}
\end{gathered}
$$

$\mathrm{Na}$ teoria X-DLVO foi considerada, além das forças atrativas de van der Waals e da força eletrostática, a energia de interação ácido-base $\left(G^{\mathrm{AB}}\right)$ entre as partículas (equação 11).

$$
G^{A B}=\pi r \Delta G_{a d h}^{A B} e^{\frac{\left(d_{0}-H\right)}{\lambda}}
$$

Onde $\lambda$ é o parâmetro de comprimento de moléculas presentes em um líquido $(6 \AA)$.

\section{RESULTADOS E DISCUSSÃO}

\subsection{Ensaios de Mobilidade Eletroforética}

A Figura 2 apresenta as curvas de potencial zeta do reagente e dos minerais de hematita e quartzo antes e após interação, em diferentes valores de $\mathrm{pH}$. A curva de potencial zeta do reagente foi interpolada com uma função polinomial e seu resultado sugere que o PIE (ponto isoelétrico) seria por volta de um $\mathrm{pH}$ de 0,5 , indicando que sua superfície estaria carregada negativamente em uma ampla faixa de $\mathrm{pH}$.

As alterações na carga de superfície do mineral podem ajudar a elucidar os mecanismos de interação entre o reagente e os sítios ativos da superfície mineral (MERMA et al., 2013). Observa-se na Figura 2, que o PIE da hematita sofreu um deslocamento que passou de $\mathrm{pH} 4,9$ (hematita pura) para pH próximo a 3,7 (após interação). Um mecanismo possível para a mudança do PIE pode estar atribuído a interação com adsorção específica. Essa discussão também foi levantada por BOTERO et al. (2008) e DEO e NATARAJAN (1997).

Já a curva de potencial do quartzo antes e após interação com o reagente não revelou mudança de PIE, sendo assim, observa-se ausência de interação específica (MESQUITA, 2003). 


\section{Potencial Zeta}

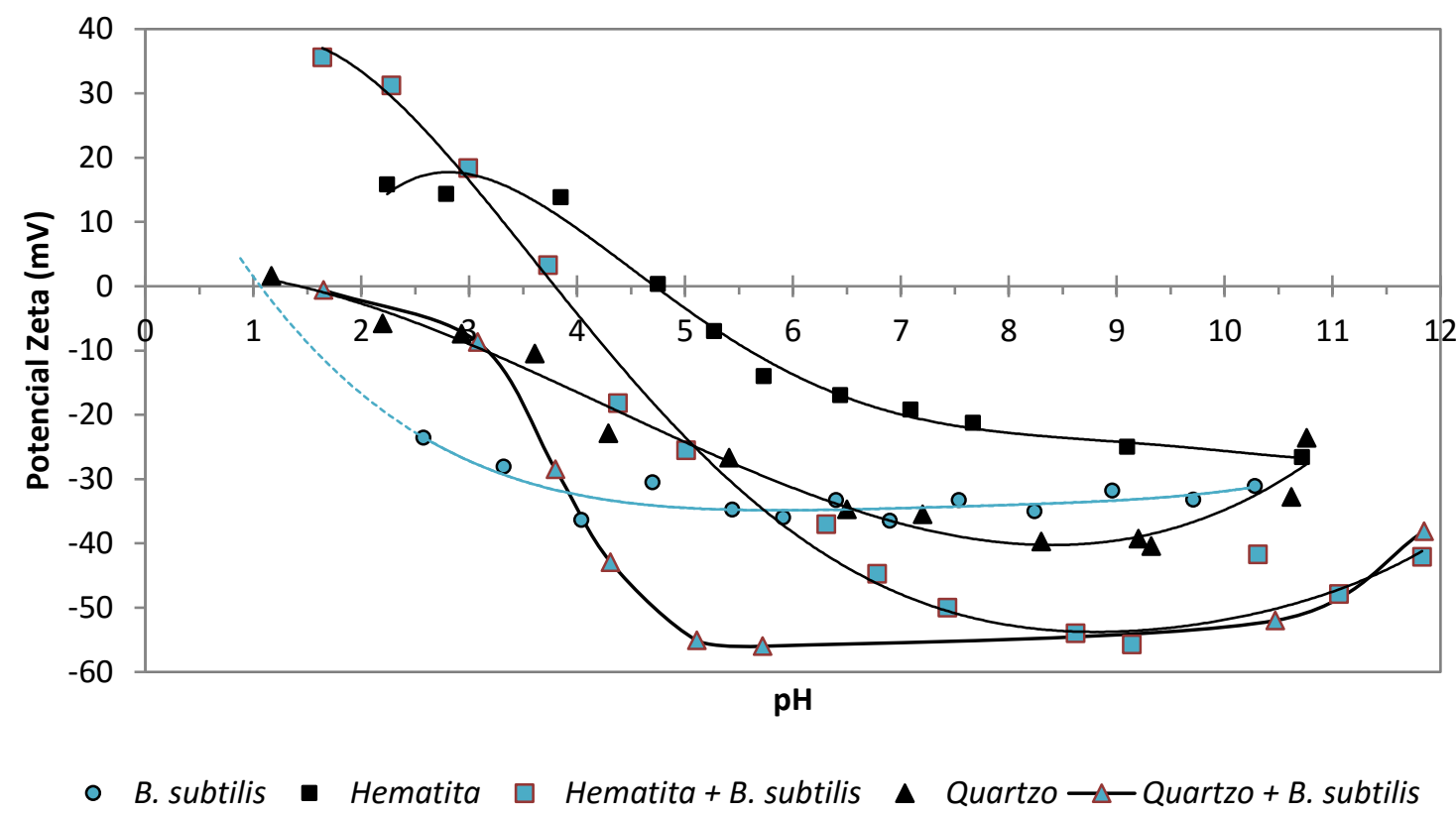

Figura 1. Potencial zeta da hematita antes e após interação com $B$. subtilis. $1.10^{-3} \mathrm{M} \mathrm{NaCl}$ como eletrólito indiferente. Concentração bacteriana $600 \mathrm{mg} \cdot \mathrm{L}^{-1}$.

\subsection{Ensaios de Ângulo de Contato}

A tabela 3 mostra o resultado das medidas de ângulo de contato para as superfícies estudadas.

Tabela 3. Ângulo de contato $\left(\theta^{\circ}\right)$ medidos com água Milli-Q em Bacillus subtilis, nos minerais antes e após interação com a cepa $B$. subtilis

\begin{tabular}{ccc}
\hline \multicolumn{2}{c}{ AMOSTRA } & ÂNGULO DE CONTATO $\left(^{\circ}\right)$ \\
\hline B. subtilis & & $41,0 \pm 3,23$ \\
\hline \multirow{2}{*}{ Hematita } & Antes da interação & $27,4 \pm 7,55$ \\
\cline { 2 - 3 } & Após da interação & $46,04 \pm 6,99$ \\
\hline \multirow{2}{*}{ Quartzo } & Antes da interação & $13,91 \pm 4,08$ \\
\cline { 2 - 3 } & Após da interação & $23,24 \pm 7,79$ \\
\hline
\end{tabular}

De acordo com a tabela, observa-se que tanto a hematita quanto o quartzo apresentaram ângulos de contato baixos que caracterizam superfícies hidrofílicas. Já o resultado de $B$. subtilis, observa-se uma característica mais hidrofóbica para a cepa em conseqüência do seu ângulo de contato maior.

Assim como os resultados dos ensaios de mobilidade eletrocinética, os de ângulo de contato indicam que há uma forte interação entre o reagente e a superfície de hematita. $O$ ângulo deste mineral passou de $27,40^{\circ}$ para $46,04^{\circ}$, indicando que 0 reagente teria atribuído um caráter hidrofóbico à hematita. Já, para o quartzo, a variação do ângulo foi inferior quando comparada com hematita. 


\subsection{Ensaios de Microflotação}

Foi encontrada uma recuperação de cerca de $80 \%$ para flotação de hematita, e de $40 \%$ para o quartzo. Além disso, uma mistura sintética de quartzo e hematita (na proporção 1:1 em massa) foi utilizada para o estudo de seletividade na flotação, sob concentração conhecida de reagente e em pH 6. Nestas condições, foi obtida recuperação de hematita de $72 \%$ no concentrado flotado, com $65 \%$ de hematita.

\subsection{Estimativa das Energias de Interação}

A Tabela 4 apresenta os valores de ângulos de contato obtidos para os líquidos polares gliceróis e água, e o líquido apolar diiodometano. A partir dos ângulos de contato foram calculadas as energias ou tensões superficiais dos sólidos e, consequentemente, as constantes de Hamaker individual e efetiva (Tabela 5).

Tabela 4. Ângulos de contato das superfícies de hematita, quartzo e do reagente para cada uma das fases líquidas utilizadas

\begin{tabular}{cccc}
\hline & ÁGUA $\left(^{\circ}\right)$ & GLICEROL $\left(^{\circ}\right)$ & DIIODOMETANO $\left(^{\circ}\right)$ \\
\hline Hematita & $27,40^{\circ} \pm 7,55$ & $22,63^{\circ} \pm 2,27$ & $60,15^{\circ} \pm 2,33$ \\
\hline Quartzo & $13,91^{\circ} \pm 4,08$ & $26,96^{\circ} \pm 3,21$ & $54,51^{\circ} \pm 2,16$ \\
\hline Reagente & $41,00^{\circ} \pm 3,23$ & $78,00^{\circ} \pm 2,57$ & $52,04^{\circ} \pm 2,90$ \\
\hline
\end{tabular}

Tabela 5. Valores das componentes de tensão superficial para hematita, quartzo e reagente. Bem como as constantes de Hamaker individual $\left(A_{11}\right)$ e efetiva $\left(A_{132}\right)$

\begin{tabular}{|c|c|c|c|c|c|c|c|}
\hline \multirow[t]{2}{*}{ SUPERFÍCIE } & \multicolumn{5}{|c|}{ ENERGIA DE SUPERFÍCIE (mJ.m-2) } & \multicolumn{2}{|c|}{ CONSTANTE DE HAMAKER $\left(10^{-20} \mathrm{~J}\right)$} \\
\hline & $\gamma^{\text {Total }}$ & $\gamma^{L W}$ & $\gamma^{A B}$ & $\gamma^{+}$ & $\gamma^{-}$ & $\left(A_{11}\right)$ & $\left(A_{132}\right)$ Reagente \\
\hline Hematita & 58,33 & 28,43 & 29,92 & 5,62 & 39,83 & 5,83 & 3,40 \\
\hline Quartzo & 57,26 & 31,66 & 25,60 & 3,13 & 52,33 & 6,49 & 4,30 \\
\hline Reagente & 63,15 & 33,06 & 30,09 & 2,79 & 81,13 & 6,78 & - \\
\hline
\end{tabular}

Todas as superfícies apresentaram valores da componente apolar de doação de elétrons $\left(\gamma^{-}\right)$superior a $28,3 \mathrm{~mJ}^{-2} \mathrm{~m}^{-2}$ e parecem se comportar como fases polares e partículas hidrofílicas (van OSS, 1994).

Para os valores positivos da constante de Hamaker efetiva $\left(A_{132}\right)$, as partículas que estão em interação se atraem por força de van der Waals (ISRAELACHVILI, 1989). Logo, há uma atração de van der Waals entre quartzo-reagente e hematita-reagente. PLAZA et al. (1998) corroboram o resultado da constante de Hamaker individual encontrado para hematita e, FARAHAT et al. (2009), para a constante do quartzo.

Os resultados encontrados pela aproximação termodinâmica entre hematita e o reagente para as energias $\Delta \mathrm{G}_{\text {adh }}{ }^{\text {Total }}, \Delta \mathrm{G}_{\text {adh }}{ }^{\mathrm{LW}}$ e $\Delta \mathrm{G}_{\mathrm{adh}}{ }^{\mathrm{AB}}$, foram de, -6,97 mJ.m ${ }^{-2}$, $1,43 \mathrm{~mJ} \cdot \mathrm{m}^{-2}$ e $-5,54 \mathrm{~mJ} \cdot \mathrm{m}^{-2}$, e, entre quartzo e o reagente de $-8,96 \mathrm{~mJ} \cdot \mathrm{m}^{-2},-2,07$ $\mathrm{mJ} \cdot \mathrm{m}^{-2}$ e $-6,89 \mathrm{~mJ} \cdot \mathrm{m}^{-2}$, respectivamente para ambas as interações. Observa-se que todos os sistemas apresentaram energia livre de adesão negativa. Logo, em todos os sistemas ocorreria uma adesão espontânea.

A estimativa da energia de interação em função da distância aplicada pelas teorias DLVO e X-DLVO apresenta-se nas figuras 2A e $2 \mathrm{~B}$. 


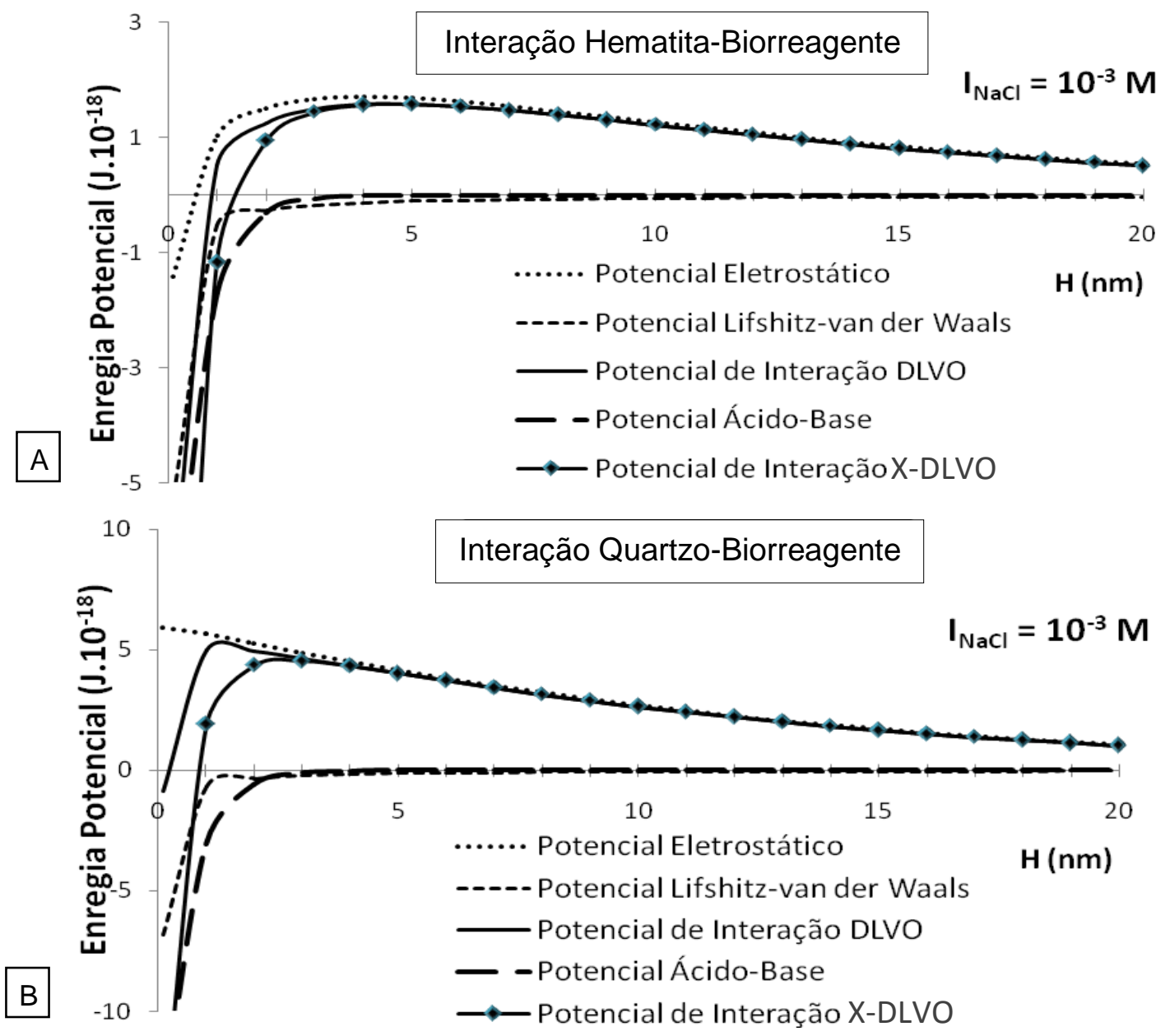

Figura 2. Curva de energia em função da distância para os sistemas hematita-reagente $(A)$ e para o sistema quartzo-reagente (B), ambos em pH 6.

Observa-se que a força de adesão ocorre em distâncias próximas a $1 \mathrm{~nm}$ para interação do reagente com as duas superfícies minerais.

Observa-se que a interação quartzo-reagente apresentou um pico primário de energia mais negativo, pela teoria X-DLVO, quando comparado com o sistema hematita-reagente. Entretanto, a barreira energética que o quartzo precisa superar, para que haja adesão com o reagente, é mais que o dobro que a barreira da hematita.

\section{CONCLUSÃo}

Os ensaios de ângulo de contato posterior ao condicionamento entre a reagente e hematita indicaram que o mineral teve suas propriedades físico-químicas de superfície alteradas tornando-se hidrofóbica. A flotabilidade 1:1 (massa), em concentração conhecida de reagente e pH 6, resultou em um teor de hematita no concentrado de $65 \%$ com uma recuperação metalúrgica de $72 \%$. As curvas de interação DLVO e X-DLVO entre a hematita e o reagente mostraram que, embora haja uma forte influência contrária à adesão por forças eletrostáticas, as teorias prevêem uma interação com adesão irreversível após vencer a barreira energética do mínimo primário. Portanto, os resultados deste trabalho mostram o potencial uso desse novo reagente como coletor de hematita. 


\section{Agradecimentos}

Os autores agradecem ao CNPq, CAPES, FAPERJ e a PUC-Rio pelo apoio financeiro, ao CETEM, Biolnovar e COPPE pelo apoio laboratorial e a VALE pelo apoio institucional.

\section{REFERÊNCIAS}

1 Brod, E.R. Circuito Alternativo para Flotação de Minério de Ferro. Dissertação (Mestrado) - Departamento de Engenharia de Minas, Universidade Federal de Ouro Preto, Minas Gerais (Brasil). 2012. 122p.

2 Carvalho, P.L.; Silva, M.M.; Rocio, M.A.R.; Moszkowicz. Minério de Ferro. In: Ambrozio, A.M.H. (Eds). BNDS Setorial. Rio de Janeiro, RJ, Brasil: Banco Nacional de Desenvolvimento Econômico e Social. 2014: (39): 197-234.

3 Farahat, M.; Hirajima, T.; Sasaki, K.; DOI, K. Adhesion of Escherichia coli onto quartz, hematite and corundum: Extended DLVO theory and flotation behavior. Colloids and Surfaces B. v.74, p.140-149, 2009.

4 Gericke, Y.; Govender, M. Extracellular polymeric substances (EPS) from bioleaching systems and its application in bioflotation. Miner. Eng. 2011:24(11):1122-1127.

5 Israelachvili, J.N. Intermolecular and Surface Forces. 3ª impressão. San Diego: Academic Press, 1989.

6 Merma, A.G.; Torem, M.L., Morán, J.J.V., Monte, M.B.M. On the fundamental aspects of apatite and quartz flotation using a Gram positive strain as a bioreagent. Miner. Eng. 2013:48: 61-67.

7 Mesquita, L.M.S. de.; Lins, F.F.; Torem, M.L. Interaction of a hydrophobic bacterium strain in a hematite-quartz flotation system. International Journal of Mineral Processing. 2003:71(1-4):31-44.

$8 \quad$ Plaza, R.C.; Zurita, L.; Durán, J.D.G.; Caballero, F.G.; Delgado, A.V. Surface thermodynamics of Hematite/Yttreium Oxide Core-Shell Colloidal Particules. Langmuir. 1998:14:6850-6854.

9 van OSS, C.J. Interfacial Forces in Aqueous Media. New York: Marcel Dekker, 1994.

10 Vilinska, A. Bacteria-Sulfide Mineral Interactions with Reference to Flotation and Flocculation. Tese (Doutorado). Departament of Chemical Engineering and GeoSciences. Lulea University of Technology. 2007. 97p. 